\title{
A publicidade como signo transbordante. Ecologia publicitária na pesquisa e na prática ${ }^{1}$
}

\author{
Advertising as an overflowing sign. \\ Advertisin ecology in research and practice
}

Clotilde Perez ${ }^{2}$, Silvio Koiti Sato ${ }^{3}$

\begin{abstract}
RESUMO
Este artigo tem como ponto de partida as múltiplas expressividades e interações midiáticas que ocorrem cotidianamente em grande velocidade e transversalidade, envolvendo marcas e consumidores em meios e plataformas as mais variadas, numa complexa ecologia publicitária. $\mathrm{O}$ recorte que utilizaremos é o entendimento do signo-Publicidade como uma entidade transbordante, que se amplifica e evolui ao pensarmos na tríade peirceana: como estética, linguagem e formato; como relação, finalidade e experiência; e como lógica, valor e estrutura que se expande para muito além do seu território inicial. Para isso, problematizamos o assunto abordando evoluções e alterações significativas nas estratégias de comunicação desenvolvidas pelas empresas, agências e múltiplos parceiros de comunicação e, por outro lado, retomamos movimentações teóricas sobre a Publicidade a fim de compreender o fenômeno do transbordamento e suas consequências.
\end{abstract}

Palavras-chave: ecologia publicitária; publicidade; signo transbordante; consumo; marcas.

\begin{abstract}
This article takes as its starting point the multiple expressions and media interactions that occur daily at great speed and transversality, involving brands and consumers in the most varied media and platfoms, in a complex advertising ecology. The outline that we will use is the understanding of the sign-advertising as na overflowing entity, wich amplifies and evolves when we think about the peirceian triad: as aesthetics, language and format; as relationship, purpose and experience; and as logic, value na structure that expands far beyond its initial territory. For this, we problematize the subject addressing significant evolutions and charges in the communication strategies developed by companies, agencies and multiple communication parters and, on the

\footnotetext{
${ }^{1}$ Baseado em trabalho anteriormente apresentado no GP Publicidade e Propaganda, XXI Encontro dos Grupos de Pesquisas em Comunicação, evento componente do $44^{\circ}$ Congresso Brasileiro de Ciências da Comunicação, 2021.

${ }^{2}$ Professora titular de Publicidade e Semiótica do CRP ECA USP. Coordenadora do PPGCom USP. Líder do GESC ${ }^{3}$ - Grupo de Estudos Semióticos em Comunicação, Cultura e Consumo. Vice-presidente da FELS - Federación Latinoamericana de Semiótica. Presidente da ABP2 - Associação Brasileira dos Pesquisadores em Publicidade e Propaganda. E-mail: cloperez@usp.br

${ }^{3}$ Doutor e Mestre em Ciências da Comunicação pela Universidade de São Paulo (PPGCOM-USP). Professor da ESPMSP. Membro do GESC ${ }^{3}$ - Grupo de Estudos Semióticos em Comunicação, Cultura e Consumo. E-mail: silviosato@yahoo.com
} 
other hand, we resume theoretical movements about advertising in order to understand the phenomenon of overflow and its consequences.

Keywords: advertising ecology; advertising; overflowing sign; consumption; brands

\section{INTRODUÇÃO}

Ao pensar na prática publicitária ao longo do tempo, é preciso lembrar que a publicidade como a conhecemos está associada à história do desenvolvimento industrial e comercial, em sintonia com as práticas de produção e consumo que foram desenvolvidas ao longo do tempo e amplificadas com a escala industrial, do desenvolvimento dos meios de transporte, da distribuição amplificada, do consequente aumento da competição e, particularmente, com os meios de informação e comunicação. Nesta imbricação de fatores e interesses econômicos, político e sociais, a publicidade é ao mesmo tempo ferramenta e sistema que alça o consumo como prática que define boa parte do indivíduo em sua subjetividade e em seus relacionamentos. Para isso, os produtos, serviços e experiências consumidas e, principalmente, as marcas, precisam ser visíveis e destacadas, sobretudo num contexto competitivo acirrado e abundante, com pouca diferenciação tecnológica entre os produtos e com o excesso de estímulos e possibilidades de comunicação em múltiplas vias, meios e canais. Com isso, a atividade publicitária torna-se um setor profissional e econômico cada vez mais importante para os interesses mercadológicos das empresas, exigindo atenção, equipes e recursos financeiros vultosos para atingir seus objetivos ambiciosos, muitas vezes em nível global.

Neste artigo, partiremos do contexto apontado anteriormente para entender as características do signo-Publicidade como uma entidade transbordante. Para isso, iniciaremos com uma revisão sobre a discussão teórica mais recente sobre o tema Publicidade e sua complexificação e evolução. Na sequência, discutiremos como as estratégias de comunicação das marcas apontam sinais recorrentes do transbordamento em suas práticas de mercado. Finalmente, chegaremos à discussão sobre o signoPublicidade, com a organização do entendimento sobre as dimensões que caracterizam o entornar do que entendíamos até há pouco como Publicidade. 


\section{Publicidade: discussão teórica recente}

A publicidade durante décadas esteve associada às funções táticas de amplificação do prazer advindo do consumo, redução de interdições de acesso, minimização de esforços ou ainda a busca por enfatizar necessidades, muitas vezes relativas ou mesmo "desnecessárias". Suas funções essenciais centravam-se em informar, persuadir, gerar lembrança e agregar valor aos produtos e, posteriormente, às marcas. Muitos estudos se destinaram às reflexões das consequências estritamente persuasivas e manipulatórias da publicidade, sendo Baudrillard (2002) um dos expoentes desta linha crítica, mas também inúmeros outros autores, vários sob o paradigma marxista como Haug (1997), Barthes (1964, 1972) com “A ilusão referencial do efeito realidade... A terra prometida da publicidade" com Bauman (2008), Klein (2002) e tantos outros.

O paradoxo permanência e fugacidade bem explorado em Perez (2004, p. 106-110 e 2011, p.69-71) também é uma característica da publicidade: comunica a perenidade, a "última" inovação, mas é sempre fugaz porque em muito pouco tempo nova possibilidade de completude se instaura com toda a força midiática. "O que parecia permanente se revela de repente efêmero" (PEREZ, 2004, p.107). É como se a publicidade se afirmasse construindo provisionalidades que se autoproclamam eternas, gerando a tensão paradoxal entre o definitivo e a certeza da inconstância, imposta pela necessidade da inovação.

No entanto, com o fim do target (PEREZ, 2009), o surgimento dos multivíduos (CANEVACCI, 2005, 2008) com suas identidades plurais, híbridas, móveis, itinerantes, deslocadas, corpos flutuantes (HALL, 2002), sempre em trânsito permanente, pelos contextos sociais também fluidos, dispersos, virtuais, presenciais e semipresenciais e a cultura digital que modifica a sensibilidade cognitiva de cada um (SANTAELLA, 2010) é impossível pensar que os alicerces e também as práticas publicitárias tenham se mantido inalteradas. O que constatamos é que só um olhar oblíquo, fluido e sincrético é capaz de captar tais transformações identitárias, tão essenciais para a comunicação de qualquer natureza (PEREZ \& BARBOSA, 2007).

Como um fenômeno característico da civilização moderna, a publicidade produz e reflete a sociedade (PEREZ, 2004, p.105 e 2011, p.61; TRINDADE, 2005, p.87). Há mais de uma década esta afirmação indiciava a compreensão da publicidade não apenas como espelho da sociedade, mas também como seu duplo, no sentido de reforço da realidade social, mas na sua capacidade construtora desta mesma sociedade. Em esforço teórico subsequente materializado nos livros Hiperpublicidade 1 e Hiperpublicidade 2 (PEREZ \& BARBOSA, 2007a e 2007b) as reflexões avançavam no sentido de identificar 
o crescimento da publicidade (aqui expresso já no título com o prefixo "hiper" em conexão com os tempos hipermodernos de Lipovetsky \& Charles, 2004). E este crescimento estava relacionado em parte ao trânsito dos objetos publicitários: desde a afirmação "mais que anunciar produtos, significar marcas" (PEREZ, 2004, p.111), a movimentação e o esforço de construir universos de sentido das/para as marcas era evidente. Causa e consequência da sociedade alicerçada no conhecimento e nos serviços, as marcas assumiram a centralidade no consumo, instaurando um novo fundamento: a comunicação da imaterialidade, o valor da subjetividade, o crescimento simbólico e o entendimento dos valores sociais como caminho consequente para a construção de posicionamentos mercadológicos vigorosos. Já havia aqui a constatação do transbordamento: "as marcas acabam por se desencarnar dos produtos que lhe deram origem, passando a significar algo muito além deles próprios” (PEREZ, 2004, p.111). Como também pode ser evidenciado na visão de Lipovetsky sobre a publicidade atual:

A publicidade passou de uma comunicação construída em torno do produto e de seus benefícios funcionais a campanhas que difundem valores e uma visão que enfatiza o espetacular, a emoção, o sentido não literal, de todo modo significantes que ultrapassam a realidade objetiva dos produtos. (LIPOVETSKY, 2009, p. 217)

Outros esforços teóricos são encontrados, sendo que um deles é especialmente interessante, o de sistema publicitário. Nesse sentido, sistema publicitário contempla todos os públicos e processos envolvidos na busca de promover o "encontro profícuo" entre os fluxos de comunicação, as pessoas e a oferta material/marcas. Baseado na ideia de meeting points - pontos de encontro (DI NALLO, 1999), busca lidar com a complexidade e a diversidade das interações comunicacionais instauradas na contemporaneidade: digital, efemeridade, fusão produção-consumo... Em sentido semelhante, mas trazendo a dinâmica dada pela ação, o conceito de Publicização (CASAQUI, 2009), baseado na Teoria das Mediações de Martín-Barbero (2001), definese como processo publicitário que deve ser compreendido em seu contexto mais amplo: como mediador das relações entre produção e consumo, ou seja, como linguagem que torna possível a realização plena das duas esferas.

O discurso publicitário é a voz que representa a estética da mercadoria e lhe atribui traços, características humanas que "lançam olhares amorosos aos consumidores", em consonância com a leitura da obra marxista por Haug (1997). 
As mudanças trazidas pelas tecnologias de informação e comunicação, sobretudo as digitais, são objeto de reflexão também da área. O livro "Ciberpublicidade: discurso, experiência e consumo na cultura transmidia" (NERY ATEM, OLIVEIRA \& AZEVEDO, 2014) trouxe inúmeras reflexões acerca do fazer e pensar publicitário. Os autores destacam algumas rupturas da ciberpublicidade com a publicidade tradicional, com ênfase para a relação com as mídias digitais e a presença online das marcas. Outra ruptura é a hibridização no trabalho publicitário da função do planejador com a de mídia e a do criativo, materializada nas narrativas transmídiáticas, saindo dos fluxos lineares rumo aos fluxos circulares. Everardo Rocha e Claudia Pereira (2013, 2009), sempre na articulação entre Comunicação e Antropologia no entendimento da Publicidade, traz contribuições importantes que fazem avançar o pensamento comunicacional no que se refere ao entendimento das pessoas e suas relações com a cultura material. Monica Machado, Patricia Burrowes e Lucimara Rett (2017) construíram o conceito de Publicidade Expandida como agregar das literacias dos discursos marcários. Também Rogério Covaleski, da Universidade Federal de Pernambuco, com as publicações Publicidade Hibrida (2010) e Idiossincrasias Publicitárias (2013) põe em evidência as movimentações de formatos e estratégias publicitárias hibridizadas e reconfiguradas em novos patamares, com destaque para o Branded Content, Product Placement e Advertainment. Em outra perspectiva, com o conceito de Promocionalidade, Maria Lilia Dias de Castro $(2009,2013)$ da Universidade Federal de Santa Maria, alinhada à semiótica francesa e ao estruturalismo, nos apresenta os caminhos integrativos da publicidade a partir do entendimento de seu fundamento inaugural: promover. Destacase ainda o trabalho de Laura Wottrich (2019), com um capítulo totalmente dedicado a problematização do lugar teórico da publicidade, percorrendo vários dos conceitos anteriormente apresentados e ainda outros.

Esta breve revisão não tem o objetivo de dar conta de todas as reflexões teóricas recentes sobre a Publicidade, mas evidenciar a "insatisfação" com o que a Publicidade enseja e o que é hoje de fato a partir das práticas de mercado, o que discutiremos a seguir.

\section{Publicidade: a comunicação das marcas na prática}

O mercado, com sua identidade fugidia e imprecisa, se reinventa rapidamente e impõe novas possibilidades de comunicação publicitária com toda a diversidade de ações possíveis que buscam pôr em contato marcas e públicos, operacionalizando criações, planejamentos e execuções transmidiáticas. Estas estratégias utilizam cada vez mais 
estruturas narrativas que mesclam o entretenimento e a informação com a mensagem de uma marca em múltiplas plataformas e pontos de contato. São conteúdos que vão além da mensagem publicitária e que usam formatos consagrados de entretenimento, como clipes, narrativas cinematográficas e televisivas, games, shows e happenings baseados em humor, música, aventura ou drama, por exemplo, para atrair espectadores e promover sua viralização de forma espontânea, sobretudo nos meios digitais, gerando visibilidade, repercussão e resultados comerciais mais expressivos.

De forma geral, ao lidar com um consumidor centrado na busca pelo prazer e pelo novo, imerso num mundo de excesso de estímulos e informações, as marcas oferecem experiências em plataformas e canais múltiplos para ter chances de chamar a atenção. Ou seja, as marcas precisam integrar seus pontos físicos (como lojas conceito com propostas multissensoriais) e também virtuais (como aplicativos móveis para acesso via smartphone), construindo territórios marcários híbridos. Com isso, temos marcas presentes em todos os locais e ocasiões possíveis, em ações de rua, com blitze, flashmobs, intervenções no mobiliário urbano e arquitetura, performances, experimentações e vivências, até o mundo virtual, com o uso de realidade virtual, QR codes e ações envolvendo plataformas digitais e apps dos mais diversos.

Um exemplo que pode ilustrar o assunto é a estratégia de comunicação utilizada pela marca de fast fashion C\&A no programa Big Brother Brasil (BBB) nos últimos anos. Além de ser uma das patrocinadoras da atração, formato tradicional no meio televisivo, a marca desenvolveu um conjunto de ações que expande e potencializa sua associação com o programa e seus participantes, que teve grandes audiências nas últimas edições (2020 e 2021). Além do que habitualmente se espera de um patrocinador (comerciais nos intervalos do programa, vinhetas nas chamadas, patrocínio de provas no decorrer do programa e ações de merchandising televisivo), a marca desenvolveu ações que usam as novas tecnologias e promovem interatividade, como a realização de um desfile virtual com hologramas para mostrar aos participantes os novos itens de sua coleção (Figura 1). $\mathrm{Na}$ ocasião, os expectadores puderam também utilizar um QR Code para acessar e comprar os itens da coleção no app da marca enquanto assistiam à atração na TV. Esta integração ocorre também em desdobramentos nas redes sociais da marca e com um conjunto de influenciadores digitais contratado pela empresa. 


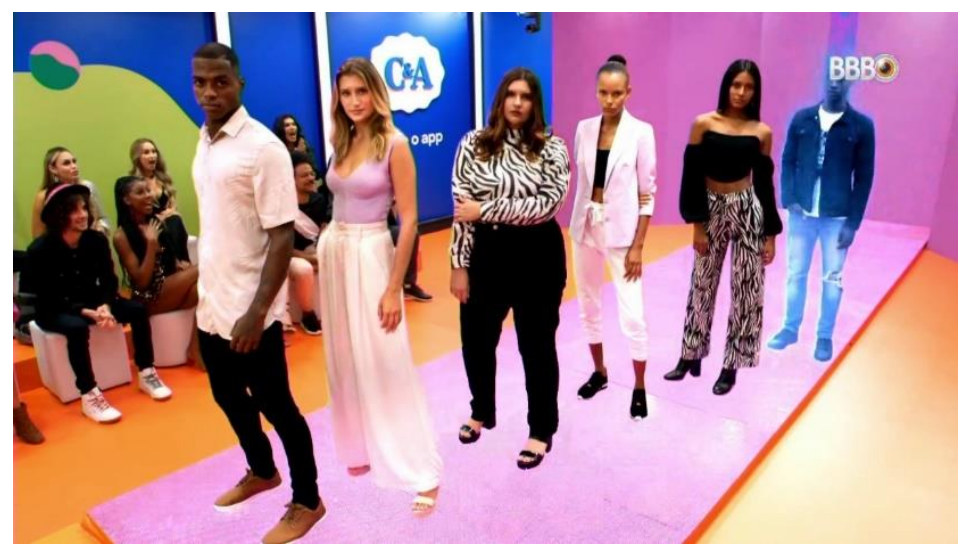

Figura 1: Desfile virtual realizado pela C\&A no BBB21

Fonte: https://propmark.com.br/digital/desfile-de-hologramas-da-ca-no-bbb-impulsiona-app-damarca/

Outra associação importante entre a marca e o programa são as coleções de roupas desenvolvidas por participantes da atração, como Manu Gavassi, na edição de 2020, e Juliette, vencedora da edição de 2021. Ambas trouxeram grande visibilidade para a marca de forma orgânica, sobretudo nas redes sociais digitais que são o ambiente de destaque de ambas. Com isso, a marca se posiciona como uma "fashion tech", uma empresa de moda que domina a tecnologia, numa estratégia multicanal que integra os pontos físicos onde a marca surgiu originalmente com as inúmeras possibilidades do comércio virtual, impulsionado no mundo pelo contexto pandêmico.

A partir deste exemplo, podemos destacar o uso de tecnologias recentes como robôs e drones, tecnologias vestíveis (wearable) conectadas a aplicativos e sites, e tantas outras. Outro aspecto tecnológico importante e menos visível para olhos pouco atentos é a maior personalização da comunicação, por um lado, e a vigilância e monitoramento constante do comportamento dos consumidores e possíveis alterações e direcionamento destes a partir da gestão de uma quantidade abundante de dados. Ou seja, algoritmos são aperfeiçoados a partir de dados armazenados no monitoramento das respostas à publicidade e do acesso a sites, redes sociais e de conteúdos que os consumidores compartilham ou mesmo dos produtos que os atraem. Com isso, ofertas e promoções próximas ao histórico de cada pessoa são veiculadas, aproximando o mundo da publicidade da estatística e dos cálculos matemáticos.

O que há em comum neste cenário rapidamente descrito? O uso de recursos dos mais variados, integrando digital e presencial (já depreendendo a robustez da pesquisa e

\footnotetext{
${ }^{4}$ https://www.meioemensagem.com.br/home/marketing/2021/04/23/como-a-ca-usa-bbb-para-construirimagem-de-fashion-tech.html
} 
do planejamento que estão por trás), todas com forte apelo estético, mas também relevantes para as pessoas, os consumidores dessas marcas. Ou seja, o que assume a centralidade é a possibilidade de vínculo efetivo, que se dará por meio do reconhecimento da pertinência pelos consumidores-alvo das campanhas, que por sua vez só será possível quando a pesquisa, o planejamento e a criação conhecerem profundamente os valores sociais que movem seus consumidores e tiverem acesso às tecnologias adequadas para que essa entrega seja ética e esteticamente relevante. Mais do que ter uma função persuasiva e transacional no sentido mercantil, a publicidade parece estabelecer cada vez mais seu caráter de indicador de um estilo de vida, associando-se cada vez mais a processos identitários e de sociabilidade, num relacionamento a ser construído de forma interativa e dinâmica com o indivíduo-consumidor.

Como vimos, os caminhos para pôr em contato pessoas e marcas são infinitos, confrontando e transbordando mídias, tecnologias, conceitos, paradigmas e valores sociais tradicionais. As soluções são muito mais complexas, como também o são as pessoas, até aí, só evidências. Essas ações anteriormente descritas, e tantas outras que nos deparamos cotidianamente, deixam claro que a Publicidade, como a entendíamos no passado não abriga mais essa complexidade e diversidade de possibilidades, trazendo a urgência da compreensão e da problematização do ecossistema no qual ela está inserida.

\section{Ecologia Publicitária e o Signo-Publicidade}

Com a sociedade e o pensamento complexos (MORIN \& LE MOIGNE, 2000) e todas as reflexões e constatações acerca dos meandros da vida na sociedade da pósmoderna, envolvendo as distintas perspectivas filosóficas, antropológicas, políticas e tecnológicas (LIPOVETSKY, 2009, 2013; HALL, 2000; GIDDENS,1991，2002; BAUMAN, 2008; CANEVACCI, 2005, 2008, MORIN, 2000, 2005; SLOTERDIJK, 2004), é impossível pensar em caminhos de encontro entre pessoas e marcas, nos diferentes rituais de consumo (PEREZ, 2020), que se deem de forma simples. Como vimos nas reflexões anteriores, há inquietação na universidade, responsável pelo pensamento e o avanço das ciências, constatada pela criação de vários conceitos: Publicização, Sistema Publicitário, Hiperpublicidade, Publicidade Hibrida, Ciberpublicidade, Publicidade Expandida e Promocionalidade são alguns deles. Mas também no mercado, que se encontra na lógica da pressão do tempo e dos resultados, notamos a movimentação reveladora da insatisfação com o reducionismo que a Publicidade, em uma visão clássica, incorpora. A Ecologia Publicitária é um conceito que 
se pretende integrador e apaziguador (pelo menos provisoriamente) das tensões, imprecisões e insatisfações com as pesquisas e práticas publicitárias atuais.

O conceito de Ecologia Publicitária encontra sua origem nas pesquisas empíricas e teóricas da Ecologia, ciência que busca entender as relações mútuas entre os organismos e o mundo exterior, que por sua vez é um ramo da Biologia, a tão conhecida ciência da vida. Ainda que cada vez mais em diálogo interdisciplinar (SANTAELLA, 2010, p. 14), essa filiação constitutiva é indelével. Como afirma Santaella sobre o uso metafórico da Ecologia, "nada mais natural que os estudos linguísticos e de comunicação se apropriarem do termo, pois o comportamento das línguas e de todos os demais tipos de signo e as dinâmicas comunicacionais que ensejam apresentam fortes similaridades com os organismos vivos" (SANTAELLA, 2010, p.15).

Ecologia Publicitária consegue expressar o transbordamento da Publicidade como organismo vivo e em movimento, na busca da construção de vínculos, não simplesmente dar visibilidade a produtos e marcas, estimular o desejo ou convencer. Se o objetivo máximo da Publicidade é construir vínculos de sentido entre pessoas e marcas (produtos, serviços, ideias, propostas etc. etc.), a questão que se põe, ultrapassa qualquer possibilidade de aprisionamento midiático. Ou seja, transborda. As ideias colocadas em prática que busquem esta relação (pessoas-marcas) pertencem ao cenário da Ecologia Publicitária. Assim, os conceitos de promoção, merchandising, insert, product placement, gameficação, blitz, ativação, marketing de relacionamento, branded content, loja conceito, flashmobs, apps, etc, bem como suas estruturas e suportes (internet, TV, rádio, cinema, rua, casa, todas as telas e tudo o mais que surgir) integram esta Ecologia. Não apenas anunciante - agência - veículo, agora temos os mais diferentes parceiros na construção e implementação das soluções: empresas de infraestrutura, de sistemas sofisticados de algoritmos, de monitoramento de redes sociais, de robótica, eventos, empresas de conteúdo etc. Estes tipos de empresas integram profissionais com as mais diversas formações e perfis, de Publicidade à Engenharia, passando por DJs, fotógrafos, antropólogos, semioticistas, filósofos, psicanalistas, programadores...

Toda esta complexidade é necessária diante da certeza de que estamos vivendo a minimização matérica das mercadorias a favor da expansão do sensível e das experiências estéticas cada vez mais imersivas... E a Publicidade tem que dar respostas a isso, não apenas refletindo valores, mas construindo novos e melhores valores sociais, na sua função de ativista social. O mundo está sendo remodelado pela lógica da mercantilização e da individualização extremas (permitido pelo big data e pelo novo paradigma 
algorítmico), constituindo um certo capitalismo artístico ou mais precisamente uma "transestética" na visão de LIPOVETSKY \& SERROY (2014). Os autores afirmam que estamos presenciando e vivendo "uma espécie de hiperarte que se infiltra nos interstícios da vida cotidiana...” (2014, p.27). Com isso, a estética está em tudo e agora com a força da massificação digital-presencial.

E como a ideia de ecossistema transforma o signo-Publicidade? Em primeiro lugar, é preciso relembrar que os signos se ampliam, evoluem e, com isso, geram possibilidades de semiose ilimitada, como tentamos organizar nesta sistematização das ideias desenvolvidas até agora a partir da tríade peirceana.

Ao refletir sobre a primeiridade, no nível do sensível e do qualitativo, destacamos as discussões sobre os formatos e as linguagens em transformação nas mensagens publicitárias, que possuíam até há pouco tempo, características comunicacionais que a distinguiam de outros tipos de comunicação, notadamente a persuasão, o imperativo, a repetição e redundância da mensagem. Ou seja, a publicidade é (ou era) uma forma de tornar conhecido um produto, um serviço e uma marca, com o objetivo de despertar nos consumidores o desejo pela coisa anunciada e destacar aspectos que diferenciam o produto de seus concorrentes. Tradicionalmente, ela fazia isso abertamente, em espaços pagos, sem encobrir o nome e as intenções do anunciante.

Atualmente, há cada vez mais uma integração (ou interferência) entre mensagens comerciais e conteúdo editorial. Ao inserir a mensagem publicitária junto ao conteúdo de um veículo, e utilizar uma estética semelhante, existe a tentativa de aproveitar a reputação do programa ou do veículo para trazer associações positivas para a marca e aumentar a credibilidade da mensagem. Com isso, há dificuldades para perceber se algo é uma publicidade (ou não) a partir das distintas execuções desenvolvidas, especialmente levando em consideração os formatos híbridos, que mesclam linguagens oriundas do jornalismo, cinema e artes, dentre outras possibilidades. Ou seja, a publicidade, em função de sua aparência, pode se disfarçar e parecer outra coisa, como ocorre na chamada "publicidade nativa", que surge em meio a conteúdos editoriais, principalmente na Internet, muito semelhante em sua forma e texto a qualquer outra notícia veiculada na mesma página. Esta publicidade envolve a negociação de um espaço de mídia com um conteúdo que se pareça com um veículo específico, que está sendo visitado espontaneamente pelo usuário. A marca anunciante pouco aparece (ou não aparece), descaracterizando um dos pontos chave para o reconhecimento da mensagem como 
publicidade. Um desdobramento importante desta discussão são os aspectos éticos ao produzir publicidade de forma camuflada e pouco transparente.

Voltando aos aspectos qualitativos, é preciso destacar também as inúmeras possibilidades sensoriais que ocorrem em diferentes pontos de contato, sobretudo em propostas de experiências sinestésicas que podem ir muito além do audiovisual, ao mesclar o paladar, o olfativo, o tátil e suas sobreposições, tanto em ambientes físicos quanto digitais.

Ao pensar na secundidade, no nível das relações e causalidades, destacamos a interação com indivíduos e grupos, afastando-se da ideia da audiência estática e massificada. Processos dialógicos se destacam, com pessoas que são mais que consumidores: são produtores e disseminadores de conteúdos sobre a marca. A participação e a interatividade surgem, portanto, como princípio norteador.

Há de se destacar, por outro lado, questões sociais emergentes como métodos produtivos e trabalhistas danosos e pouco sustentáveis, com uma postura mais crítica por parte de grupos de consumidores ativistas em relação às marcas, símbolos mais visíveis deste sistema. Como consequência, há a cobrança de parte da sociedade de um engajamento e comprometimento das marcas e das empresas a causas sociais que comprovem sua responsabilidade social em ato e não apenas no discurso. Ou seja, é preciso levar em consideração a associação entre o consumo, cidadania, reputação e marcas. Este crescente ceticismo em relação às marcas e à mensagem publicitária tradicional reforça a necessidade de novos pactos para a convivência entre marcas e consumidores. Neste sentido, podemos destacar a passagem do discurso persuasivo, sem espaço para contestações, para algo mais propositivo e inspirador, algo que pode ser exemplificado pelas inúmeras mensagens que trazem valores, visões, opiniões e pontos de vista sobre questões relevantes para a sociedade, afastando-se de objetivos comerciais mais óbvios e táticos.

Finalmente, ao pensar na terceiridade, no nível da generalidade e da lógica, podemos pensar na consolidação da ideia de que tudo é publicizável, dada a popularização de mecanismos associados à prática publicitária no cotidiano das pessoas. Basta pensar no que bilhões de pessoas levam em consideração ao postar uma foto ou mensagem nos seus perfis nas redes sociais digitais. Ao aplicar um filtro que melhora sua aparência, escolher a palavra ou hashtag mais adequada e pensar no melhor dia e horário para postar, cada pessoa aplica princípios de produção, criação, redação publicitária e planejamento de mídia que há pouco eram preocupações e habilidades exclusivas dos profissionais da 
área. Gerir seus perfis em diferentes redes, acompanhar os comentários, monitorar o que se fala a respeito de si próprio, tudo isso passa a ocupar um lugar importante na vida pessoal e social. A publicidade enquanto lógica passa a ser reguladora e com certo poder impositivo como um modo de existir e ocupar um espaço na amplificação da visibilidade das redes.

Da mesma maneira, o entendimento da formação publicitária ou do profissional que trabalha com publicidade passa por transformações apontadas ao longo deste artigo. Formada tradicionalmente por players como agências, veículos, anunciantes e fornecedores de comunicação, de forma razoavelmente estável ao longo do tempo, a chamada indústria publicitária se tornou mais complexa, com outros integrantes como provedores de TI, plataformas tecnológicas, consultorias e inúmeros fornecedores que trazem uma abordagem quantitativa ao processo (métricas e monitoramento) em função do volume de dados disponível e, por outro lado, possibilitam a entrada de profissionais de outras áreas de informação e entretenimento para gerar conteúdos com outras características que fogem da linguagem publicitária habitual.

Com isso, a publicidade se impõe no cotidiano, ultrapassando as fronteiras de sua atuação original, relacionada às transações comerciais entre empresas e consumidores e transborda para outras esferas, práticas, grupos, assuntos e formatos. Se expande, transborda, suscita sensações e emoções que favorecem a construção de vínculos fundamentados no prazer e no encantamento.

\section{Considerações finais}

Com o objetivo de oferecer uma nova perspectiva conceitual que atenue as tensões teóricas e fundamente as práticas publicitárias cotidianas, o presente artigo apresentou o percurso dessas movimentações tanto na perspectiva teórica, quanto na práxis, apresentando algumas manifestações e suas implicações na construção de vínculos de sentido entre marcas e pessoas.

Propõe ao final o adensamento do conceito de "Ecologia Publicitária" (PEREZ e CORREA, 2018) sustentado na publicidade enquanto signo transbordante e em constante crescimento, como pôde ser observado no percurso semiótico, passando pelas qualidades da primeiridade (como estética), a referencialidade da secundidade (como relação) e a generalização, típica de terceiridade (como lógica), categorias fenomenológicas de Charles Peirce (1995). 
Fundamentado nas reflexões teóricas de todos os autores referenciados ao longo do artigo e na análise do mercado publicitário, como a ambiência que abriga estas complexidades, acreditamos na contribuição para o avanço do campo, sem, no entanto, deixar de creditar as principais contribuições advindas dos pesquisadores brasileiros que têm a Publicidade nas suas relações com o Consumo e a Cultura, seu foco investigativo e formativo.

\section{REFERÊNCIAS}

BARTHES, R. Réthorique de l'image. Communications. Paris: Seuil, 1964 Mitologias. São Paulo: Difel, 1972

BAUDRILLARD, J. Sistema dos objetos. São Paulo: Perspectiva, 2002.

BAUMAN, Z. Vida para o consumo. A transformação das pessoas em mercadoria. Rio de Janeiro: Zahar, 2008

CANEVACCI, M. Fetichismos visuais. São Paulo: Ateliê, 2008

Culturas eXtremas. Rio de Janeiro: DP \&A, 2005

CASAQUI, V. Por uma teoria da publicização: transformações no processo publicitário. Significação: Revista de Cultura Audiovisual, v. 36, p. 131-151, 2011.

A esfera simbólica da produção - estratégias de publicização do mundo do trabalho na mídia digital. Rumores (USP), v. 6, p. 164, 2009.

CASTRO, M. L. A chamada promocional: lógicas e estratégias. Animus (Santa Maria), v. XIII, p. 69-82, 2009.

Da publicidade ao conceito de promocionalidade: percursos e desafios. In: Trindade, E.; Perez, C. (Org.). E-book. Por uma publicidade livre sempre. 3ed. São Paulo: Inmod/ABP2/PPGCom-ECA-USP, 2013, v. 1, p. 582-598.

COVALESKI, R. Publicidade híbrida. Curitiba: Maxi Editora, 2010.

Idiossincrasias publicitárias Curitiba: Maxi Editora, 2013.

DINALLO, E. Meeting points. São Paulo: Cobra, 1999

GIDDENS, A. As consequências da modernidade. São Paulo: Unesp, 1991

Modernidade e identidade. Rio de Janeiro: Jorge Zahar, 2002

HALL, S. A identidade cultural na pós-modernidade. Trad. Tomaz Tadeu da Silva e Guacira Lopes Louro. 7ª ed. Rio de Janeiro. DP\&A, 2002.

HAUG, W. F. Crítica da estética da mercadoria. São Paulo: Unesp, 1997. 
JENKINS, H. Cultura da convergência. São Paulo: Aleph, 2009.

FORD, S.; GREEN, J. Spreadable media. Creating value and meaning in a networked culture. New York: New York University Press, 2013.

KLEIN, N. No Logo. Rio de Janeiro: Record, 2002

LIPOVETSKY, G. O Império do efêmero. São Paulo: Cia das Letras, 2009

; CHARLES, S. Os tempos hipermodernos. São Paulo: Barcarolla, 2004

; SERROY, J. La cultura-mundo. Respuesta a uma sociedade desorientada. Barcelona: Anagrama, 2010

A estetização do mundo. Viver na era do Capitalismo artista. São Paulo: Cia das Letras, 2015

MACHADO, M.; BURROWES, P. RETT, L. Para ler a publicidade expandida em favor da literacia midiática dos discursos das marcas. Anais do Encontro Anual da Compós, 2017

MORIN, E.; LE MOIGNE, J.L. A Inteligência da Complexidade. São Paulo: Petrópolis, 2000.

Cultura de massas do século XX: o espírito do tempo I: neurose. Rio de Janeiro: Forense Universitária, 2005

NERY ATEM, G.; OLIVEIRA, T.M. \& AZEVEDO, S.T. (orgs.) Ciberpublicidade: discurso, experiência e consumo na cultura transmidiática. Rio de Janeiro: Faperj/e-papers, 2014.

PEIRCE, C.S. Semiótica. São Paulo: Perspectiva, 1995

PEREZ, C. Signos da Marca. São Paulo: ThomsonLearning, 2004.

Há limites para o consumo? São Paulo: Estação das Letras e Cores, 2020

Condições antropossemióticas do negro na publicidade contemporânea. In:

BATISTA, L. \& LEITE, F. (orgs.) O Negro nos espaços publicitários brasileiros. São Paulo: ECA USP/CONE, 2011. \& BARBOSA, I. Hiperpublicidade 1. São Paulo: ThomsonLearning, 2007a.

. Hiperpublicidade 2. São Paulo: ThomsonLearning, 2007b.

; TRINDADE, E. Marketing e tendências de consumo. In BRITO, C. \&

LENCASTRE, P. Novos horizontes do marketing. Lisboa: D.Quixote, 2014.

; SATO, S. Os múltiplos sentidos da cena midiática contemporânea. In Tríade, v.1, n.2, Sorocaba: Uniso, 2013.

; CORREA, V. A. Estética do consumo: uma perspectiva a partir da ecologia publicitária.

Revista Visualidades, v.2, 2018, pp. 301-3017

ROCHA, E. \& PEREIRA, C. (orgs) Cultura e imaginação publicitária. Rio de Janeiro: Mauad, 2013.

Juventude e consumo. Rio de Janeiro: Mauad, 2009.

SANTAELlA, L. A ecologia pluralista da comunicação. Conectividade, mobilidade, ubiquidade. São Paulo: Paulus, 2010.

As linguagens como antídotos ao midiacentrismo. Revista Matrizes. São Paulo, v.1, n.1, 2007, p.75-97. Disponível em: < http://www.matrizes.usp.br/index.php/ matrizes /article/view/27/39 >. Acesso em: julho de 2016. 
SANTOS, J. Sobre tendências e o espírito do tempo. São Paulo: Estação das Letras e Cores, 2013.

SCOLARI, C.A. Narrativas Transmedia: quando todos os médios cuentam. Barcelona: Centro Libros PAPF, S.L.U., 2013.

SLOTERDIJK, P. Sphären I - Blasen. Frankfurt: Suhrkamp, 1998. Sphären II - Globen. Frankfurt: Suhrkamp, 1999.

Sphären III - Schäume. Frankfurt: Suhrkamp, 2004.

TRINDADE, E. A publicidade e a modernidade-mundo: as representações de pessoa, espaço e tempo. In BARBOSA, I. (org.). Os sentidos da publicidade. São Paulo: Thomson Learning, 2005.

WOTTRICH, L. Publicidade em xeque. Práticas de contestação dos anúncios. Porto Alegre: Sulina, 2019

Recebido em: 01/11/2021

Aprovado em: 30/11/2021

Publicado em: 03/12/2021 